\title{
Incorporating a Nebulizer System Into High-Flow Nasal Cannula Improves Comfort in Infants With Bronchiolitis
}

\author{
Juan Valencia-Ramos MD, Alicia Mirás MD PhD, Amacia Cilla MD, Carlos Ochoa MD PhD, and \\ Juan Arnaez MD PhD
}

\begin{abstract}
BACKGROUND: High-flow nasal cannula (HFNC) is increasingly used to provide respiratory support in infants with bronchiolitis. The delivery of aerosol therapy through a jet nebulizer is widely indicated despite its controversial efficacy and poor tolerability. METHODS: This randomized cross-over study aimed to evaluate the comfort and satisfaction of the delivery of aerosol therapy using a nebulization system integrated into HFNC compared with the standard practice of using a jet nebulizer with a face mask. The COMFORT-Behavior (COMFORT-B) scale, a visual analog scale, and a numeric rating scale were used by health professionals and caregivers to assess subjects' levels of comfort and satisfaction. RESULTS: A total of 113 nebulizations (64 via nebulizer with HFNC; 49 via jet nebulizer) were delivered to the 6 subjects included in the study. Use of the nebulizer with HFNC showed increased comfort and satisfaction during nebulization compared to use of the jet nebulizer, as measured by the COMFORT-B scale, the visual analog scale, and the numeric rating scale, with the following median (interquartile range) scores: 10.7 (7-16) versus 14.5 $(10-20)(P=.006), 8.5(6-10)$ versus $7(4-9)(P=.02)$, and $3.84(3.61-4.07)$ versus $1.83(1.58-2.08)$ $(P<.001)$, respectively. Correlation between the COMFORT-B scale and the visual analog scale using Spearman's rho was $-0.757(P<.001)$. The intraclass correlation coefficient for the COMFORT-B scale, visual analog scale, and numeric rating scale, as measured by 2 different nurses, was between 0.75 and 0.87 . CONCLUSIONS: The use of a nebulizer incorporated into HFNC therapy results in an increased level of comfort and satisfaction compared to the use of a conventional jet nebulizer in subjects with bronchiolitis who required HFNC therapy. Further studies are needed to determine whether aerosol therapy delivered through HFNC improves the clinical course of this pathology. Key words: high-flow oxygen therapy; nebulization; comfort; bronchiolitis; satisfaction; jet nebulizer. [Respir Care 2018;63(7):886-893. (C) 2018 Daedalus Enterprises]
\end{abstract}

\section{Introduction}

Bronchiolitis is an acute inflammatory injury of the bronchioles caused by a viral infection in infants. ${ }^{1}$ It has an

\footnotetext{
Drs Valencia-Ramos and Mirás are affiliated with the Pediatric Intensive Care Unit, Centro Hospitalario Burgo, Burgos, Spain. Drs Cilla and Arnaez are affiliated with the Department of Pediatrics, Centro Hospitalario Burgos, Burgos, Spain. Dr Ochoa is affiliated with the Department of Pediatrics, Hospital Virgen de la Concha, Zamora, Spain.
}

Dr Valencia-Ramos presented a version of this paper at the Spanish Congress of Pediatric Intensive Care, held May 4-6, 2017, in Granada, Spain.

The authors disclose relationships with the Fundación Burgos por Investigación de la Salud, Fisher \& Paykel Healthcare, and Philips. annual incidence of $7-20 \%$ and a hospitalization rate of $3-5 \%,{ }^{2,3}$ with a mean hospital length of stay of $1.2-8 \mathrm{~d} .{ }^{4}$ This high use of medical care translates into a significant social and economic impact. ${ }^{5,6}$

Aerosol therapy in this disease is continually re-evaluated. Nebulization with salbutamol, epinephrine, or 3\% hypertonic saline are used in clinical practice to perform

\footnotetext{
Supplementary material related to this paper is available at http:// www.rcjournal.com.

Correspondence: Juan Valencia-Ramos MD, Centro Hospitalario Burgos, Avenida Islas Baleares s/n, Burgos, CP 09006, Spain. E-mail: jvalenra@gmail.com.
}

DOI: $10.4187 /$ respcare. 05880 
initial efficacy tests or to attempt to improve clinical severity. ${ }^{7-11}$ These drugs are generally administered with a jet nebulizer connected to a face mask, despite this modality's poor tolerability and insufficient particle deposition in the lungs in many cases..$^{12,13}$ Cooperation during administration remains the most important factor for drug delivery, ${ }^{14}$ particularly in neonates and small children, in whom the nasal route for aerosol delivery to the lower respiratory tract is more efficient than mouth breathing. ${ }^{15-17}$

The efficacy and safety of oxygen therapy via high-flow nasal cannula (HFNC) has made it one of the most frequently used respiratory supports in infants with bronchiolitis. ${ }^{18}$ Nevertheless, the use of a jet nebulizer in patients receiving HFNC requires the discontinuation of respiratory support to release the nasal route, as well as frequent awakening, which often results in the patient's increased irritability. Thus, a system to deliver both oxygen and medication without patient manipulation would reduce discomfort and could favorably affect the course of the disease. This possibility has not been well studied in vitro ${ }^{19-21}$ and in only one descriptive clinical study. ${ }^{22}$

We sought to evaluate in a randomized cross-over study the comfort and satisfaction of the delivery of aerosol therapy using a nebulization system integrated into HFNC compared with the standard practice of using a jet nebulizer with a face mask. Comfort and satisfaction were examined with different validated medical scales and assessed by health personnel and caregivers in children with bronchiolitis.

\section{Methods}

This prospective, randomized, cross-over study included 6 neonatal subjects $<24$ months old with bronchiolitis who received respiratory support with HFNC in March 2016. Two hospitals participated in the study; one was a secondary hospital where standard low-flow therapy or HFNC was used as respiratory support, and the other was a tertiary hospital where HFNC was administered in the pediatric ICU after initial stabilization with noninvasive ventilation or invasive ventilation, depending on the severity of the bronchiolitis.

Bronchiolitis was defined as a clinical syndrome that occurred in children $<2$ y old, characterized by upper respiratory symptoms followed by signs of lower respiratory infection with inflammation, resulting in wheezing or crackles. Each subject's bronchiolitis scale score (San Juan de Dios Hospital Bronchiolitis Scale ${ }^{23}(0-5=$ mild; $6-10=$ moderate; $11-16=$ severe) was registered at admission. The study was approved by the clinical research ethics committee (Comité Ético de Investigación Clínica del Área de Salud Burgos y Soria-Ref: 1558).

\section{QUICK LOOK}

\section{Current knowledge}

High-flow nasal cannula (HFNC) and aerosol therapy are part of the treatment for bronchiolitis. A jet nebulizer connected to a face mask is the most frequently used type of nebulizer, despite controversy over its efficacy and poor tolerability, which can cause discomfort in the child and stress for the whole family.

\section{What this paper contributes to our knowledge}

Aerosol therapy with a nebulizer integrated with an HFNC, compared to a traditional nebulizer, resulted in increased levels of subject comfort and satisfaction, measured with validated scales by both health care professionals and caregivers.

\section{Respiratory Support and Aerosol Therapy}

After parental consent was obtained, subjects were randomized by a computer-generated random number list to begin nebulization with a jet nebulizer or with a nebulizer + HFNC system, alternating the nebulization device in subsequent medication doses. Support with HFNC was not removed when placing the jet nebulizer face mask. The number of nebulizations and the choice of drug (salbutamol, $3 \%$ hypertonic saline, or epinephrine) in each subject depended on the subject's clinical situation and medical criteria.

The Optiflow system (MR850 humidifier with RT329 infant heated circuit; Fisher \& Paykel, Auckland, New Zealand) was used with a neonatal nasal cannula (BC2435, Fisher \& Paykel) for gas flows $<8 \mathrm{~L} / \mathrm{min}$ or an infant cannula (BC2755, Fisher \& Paykel) for gas flows $\geq 8 \mathrm{~L} / \mathrm{min}$.

The nebulizer with HFNC system consisted of a mesh nebulizer (AeroNeb Solo, Aerogen, Galway, Ireland) connected to the dry side of the MR290 humidifier chamber (Fisher \& Paykel) (Fig. 1A). The standard practice for jet nebulizer use consisted of a jet nebulizer connected to a face mask (Cirrus 2 Pediatric, Intersurgical, Wokingham, United Kingdom) with a gas flow of $8 \mathrm{~L} / \mathrm{min}$ (Fig.1B). In case of the jet nebulizer, the final flow was that of the nebulizer and HFNC.

\section{Comfort Analysis}

Comfort and satisfaction were recorded for each nebulization $5 \mathrm{~min}$ before nebulization, during, and $5 \mathrm{~min}$ after nebulization by 2 nurses or caregivers (see Appendix 1 in the supplementary materials at http://www.rcjournal.com). Comfort was analyzed using the COMFORT-Behavior 


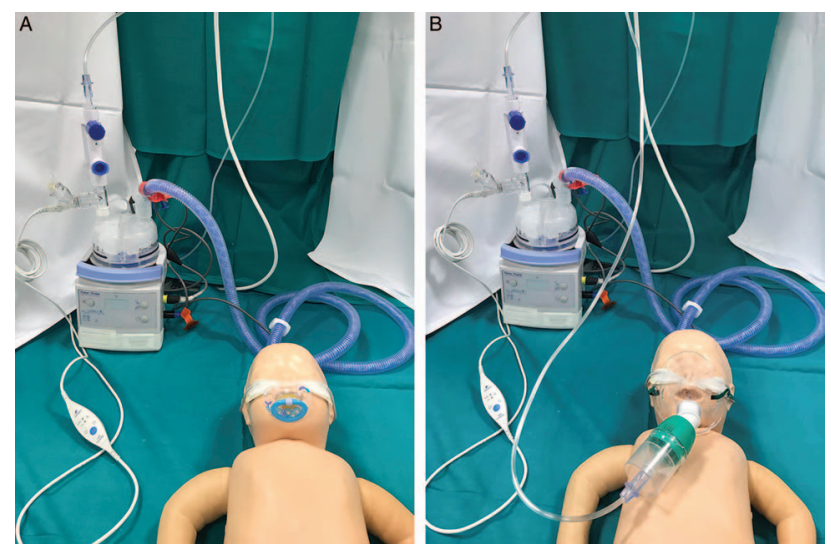

Fig. 1. Nebulizer system in a model with bronchiolitis and highflow nasal cannula (HFNC). (A) Mesh nebulizer integrated with HFNC. (B) Jet nebulizer with a face mask.

(COMFORT-B) scale ${ }^{24}$ and a visual analog scale. ${ }^{25}$ The COMFORT-B scale is scored from 1 to 5 , and the total score is the sum of the 6 behavioral items, with a range of 6 to 30 . All nurses underwent previous training through an accredited course. The visual analog scale is represented by a horizontal $10-\mathrm{cm}$ line, with "no comfort" on the left side and "extreme comfort" on the right side. Satisfaction was measured with a numeric rating scale, which is a global pain-rating scale that rates pain intensity by number $(0=$ no pain, $4=$ worst imaginable pain $)$.

One month before starting the study, involved health personnel received a training course on the different scales that would be used, as well as the methodology and schedule to be followed.

\section{Other Variables Analyzed}

For each nebulization, the following variables were recorded: date and time; food intake; analgesia administered; physiological variables (ie, heart rate, breathing frequency, oxygen saturation, and $\mathrm{F}_{\mathrm{IO}_{2}}$ ), and HFNC parameters (ie, air flow and temperature) (see Appendix 1 in the supplementary materials at http://www.rcjournal.com).

\section{Data Analysis}

Absolute and relative frequencies were calculated for each qualitative variable, and the differences based on nebulization system were identified using chi-square or Fisher exact test. For quantitative variables, medians and interquartile ranges (IQRs) were obtained according to nebulization system and time period. Spearman's coefficient was used to measure correlation among the different measuring scales, and the intraclass correlation coefficient was used to evaluate the consistency of the scores obtained by nursing staff. Nonparametric testing (Mann-Whitney $U$ test) was used to compare both nebulization systems in each time period. Repeated measures analysis of variance (ANOVA) was performed to determine the existence of differences due to the nebulization system used in relation to each subject's comfort scores, severity scores, and duration of hospital stay. With repeated measures ANOVA, it is possible to adjust the analysis by subject, controlling the existing differences by treatment, which was the same in each subject. Given that each subject received both kinds of treatments on various occasions, carry-over effect and interaction by order of administration were not expected.

The number of paired measurements that should be obtained to estimate a paired mean difference of comfort scale of 2 points (difference SD of 4 points) with a power of 0.8 and an $\alpha$ error of 0.05 was 34. Power estimation for comfort scale was made with $\mathrm{G}^{*}$ Power 3.1.9.2. ${ }^{26}$ We estimated that a sample size of 113 measurements has a post hoc achieved power of 0.99 in repeated measures ANOVA (within-between interaction), assuming an effect size of 0.245 (eta squared $=0.06$; estimated from data and equivalent to means differences $>2.4$ ), $\alpha$ error $0.05, \beta$ error $0.20,2$ groups (nebulization system), 3 measurements (pre, during, post), and a partial correlation (between measurements adjusting by subject) of 0.3 . $P$ values $<.05$ were considered to be statistically significant. Statistical analyses were performed using statistics software (SPSS version 18.0, SPSS, Chicago, Illinois).

\section{Results}

A total of 113 nebulizations were administered to 6 subjects, all of whom were male and had moderate bronchiolitis (median score 7 [IQR 8-9] points on the bronchiolitis scale). The median [IQR] age and weight at admission was 1.5 months $(1.0 ; 4.5)$ and $4.35 \mathrm{~kg}(2.85 ; 6.90)$, respectively. No subject had other underlying disease or factors of severity such as prematurity, cardiopathy, bronchopulmonary dysplasia, neuromuscular disease, or immunodeficiency.

The COMFORT-B and visual analog comfort scales used by health staff showed no differences between either method of aerosol delivery, both before and after the nebulization was given. During nebulization, comfort was greater with the nebulizer with HFNC system compared to the jet nebulizer: the median (IQR) COMFORT-B scale score was $10.7(7-16)$ versus $14.5(10-20)(P=.006)$, respectively, and the median (IQR) visual analog scale score was $8.5(6-10)$ versus $7(4-9)(P=.02)$, respectively. Satisfaction assessed with the numeric rating scale during nebulization was greater with the nebulizer with HFNC compared to the jet nebulizer, with a median (IQR) score of $3.7(3-4)$ versus $2.5(1-4)(P<.001)$, respectively (Fig. 2). See Table 1 for all of the median (IQR) 

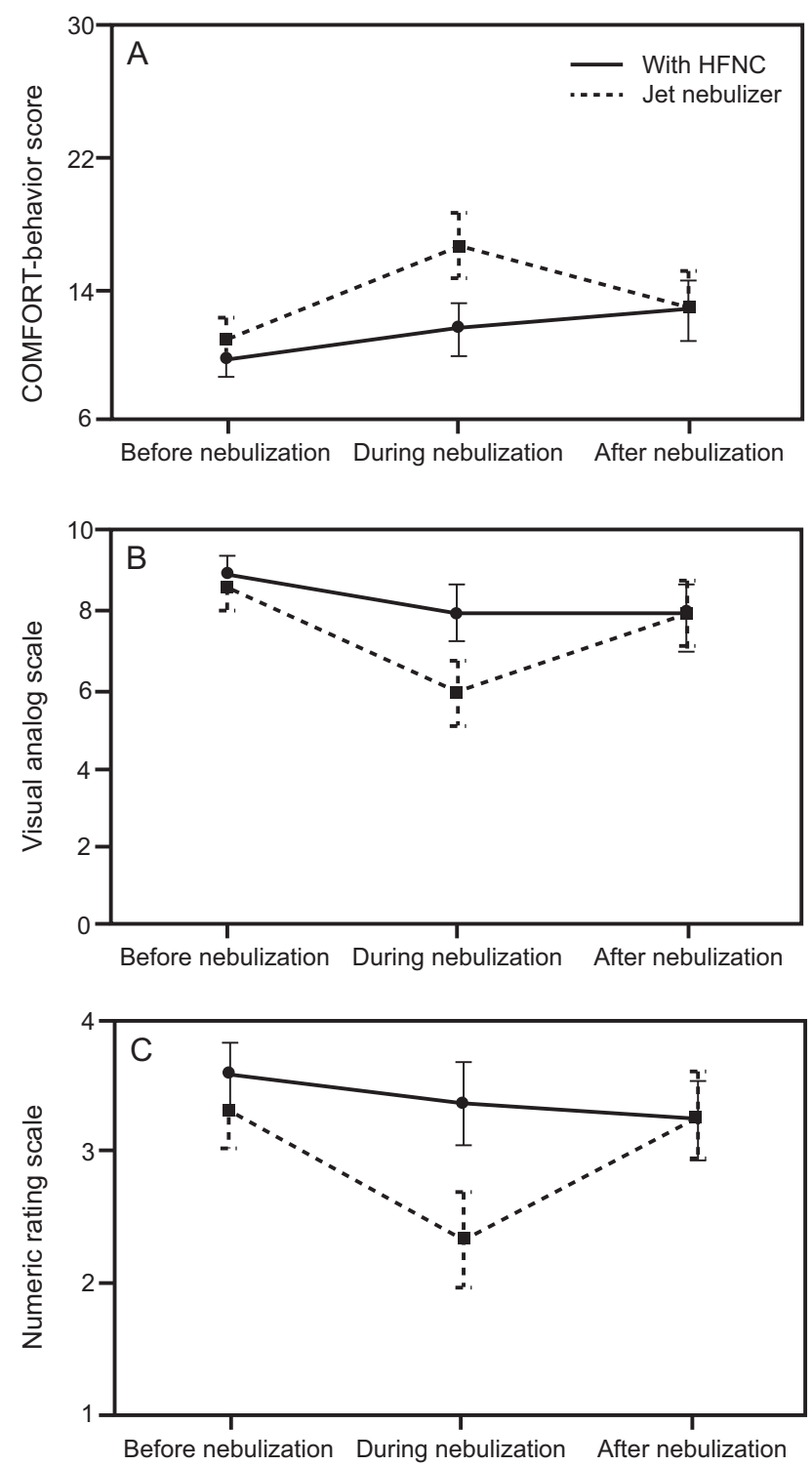

Fig. 2. Repeated measures analysis of variance points of comfort (A: COMFORT-behavior score, B: visual analog scale) and satisfaction (C: numeric rating scale). Nebulization with HFNC showed greater comfort and satisfaction compared to a jet nebulizer during nebulization $(P<.001)$.

scores. Comfort scales assessed by parents during 26 of the 113 nebulizations showed greater comfort and satisfaction with the nebulizer with HFNC compared to the jet nebulizer; scores on the COMFORT-B scale, visual analog scale, and numerical rating scale were $10.5,9$, and 4 versus $16.5(P=.004), 4(P=.001)$, and $2(P=.001)$, respectively (Table 1$)$.

Correlation (Spearman's rho) between the COMFORT-B scale and the visual analog scale was $-0.757(P<.001)$. The intraclass correlation coefficient for the COMFORT-B scale, visual analog scale, and numerical rating scale, measured by 2 different nurses, was between 0.75 and 0.87 .
There were no significant differences at baseline between the nebulizer with HFNC group and the jet nebulizer group when analyzing the nebulized drug, time since last food intake, time of day (day versus night), use of analgesia, oxygen saturation, breathing frequency, $\mathrm{F}_{\mathrm{IO}_{2}}$, and heart rate (Table 2).

A significantly increased heart rate was registered in both groups during nebulization compared to the period before nebulization $(P<.001, P<.001)$, while there were no changes in oxygen saturation, breathing frequency, and $\mathrm{F}_{\mathrm{IO}_{2}}$.

\section{Discussion}

In this randomized cross-over trial in infants with bronchiolitis, the levels of comfort and satisfaction during nebulization, as assessed by nurses and caregivers, were higher using a nebulizer integrated with HFNC than using a jet nebulizer connected to a face mask.

The advantages of HFNC, such as the ease of setup, the adequate tolerance, and minimal adverse events, have increased its use in pediatric care. ${ }^{27,28}$ The possibility of nebulization through HFNC and its differences from a jet nebulizer have recently been demonstrated in various in vitro studies, including pulmonary deposition and nebulized particle size as determinants of the efficacy of this new system. ${ }^{19,29}$ However, clinical studies are lacking. To our knowledge, there is only one previous clinical study that compares these methods of nebulization in a case series of 5 patients with bronchiolitis in a pediatric emergency department. ${ }^{22}$ Our study contributes, in a randomized and controlled way, an assessment of the comfort with different validated medical scales, performed not only by health personnel but also by relatives, in children with bronchiolitis using a nebulization system integrated into HFNC compared with standard practice.

Family satisfaction has gained increasing interest as an important indicator of outcomes in health care and for the evaluation of quality of care. ${ }^{30}$ Young children with bronchiolitis cannot verbally express their level of satisfaction with treatment, so the opinion and satisfaction of caregivers is especially important. Satisfaction refers to the amount of fulfillment of perceived or real, implicit or explicit needs and expectations of an individual or a group. Thus it is a complex variable difficult to assess with no accepted standard for measurement. ${ }^{31-33}$ Our results showed higher scores on the numerical rating scale during the administration of aerosol therapy via a nebulizer with HFNC versus standard nebulization, as evaluated by nurses and caregivers.

Delivering aerosolized medication through a conventional device (eg, a jet nebulizer) generates discomfort. ${ }^{12,34}$ It is important to point out that, according to our results, comfort levels are comparable with both devices before 
Table 1. Comfort and Satisfaction Perceived by Caregivers and Nurses

\begin{tabular}{|c|c|c|c|c|c|c|c|c|}
\hline & \multirow{2}{*}{$\begin{array}{c}\text { Time of } \\
\text { Assessment }\end{array}$} & \multicolumn{3}{|c|}{$\begin{array}{l}\text { Nebulizer With } \\
\text { HFNC }(n=63)\end{array}$} & \multicolumn{3}{|c|}{$\begin{array}{l}\text { Jet Nebulizer } \\
\quad(n=50)\end{array}$} & \multirow[t]{2}{*}{$P^{*}$} \\
\hline & & $n$ & Median & $\mathrm{IQR}$ & $n$ & Median & IQR & \\
\hline \multicolumn{9}{|l|}{ Assessments by nurses } \\
\hline \multirow[t]{3}{*}{ COMFORT-B } & Before nebulization & 60 & 7.0 & $(6-11)$ & 47 & 10.0 & $(7-14)$ & .07 \\
\hline & During nebulization & 60 & 10.7 & $(7-16)$ & 46 & 14.5 & $(10-20)$ & .006 \\
\hline & After nebulization & 59 & 10.5 & $(7-15)$ & 46 & 13.5 & $(9-16)$ & .28 \\
\hline \multirow[t]{3}{*}{ Visual analog scale } & Before nebulization & 60 & 10.0 & $(9-10)$ & 47 & 10.0 & $(8-10)$ & .61 \\
\hline & During nebulization & 60 & 8.5 & $(6-10)$ & 46 & 7.0 & $(4-9)$ & .02 \\
\hline & After nebulization & 59 & 9.0 & $(8-10)$ & 46 & 8.5 & $(7-10)$ & .46 \\
\hline \multirow[t]{3}{*}{ Numerical rating scale } & Before nebulization & 53 & 4.0 & $(4-4)$ & 43 & 4.0 & $(3-4)$ & .002 \\
\hline & During nebulization & 60 & 3.7 & $(3-4)$ & 46 & 2.5 & $(1-4)$ & $<.001$ \\
\hline & After nebulization & 54 & 4.0 & $(3-4)$ & 41 & 3.0 & $(3-4)$ & .14 \\
\hline \multicolumn{9}{|l|}{ Assessments by caregivers } \\
\hline \multirow[t]{3}{*}{ COMFORT-CBS } & Before nebulization & 14 & 8.0 & $(6-11)$ & 12 & 11.5 & $(9-16)$ & .13 \\
\hline & During nebulization & 14 & 10.5 & $(6-12)$ & 12 & 16.5 & $(13-22)$ & .004 \\
\hline & After nebulization & 12 & 6.5 & $(6-14)$ & 12 & 13.0 & $(11-14)$ & .09 \\
\hline \multirow[t]{3}{*}{ Visual analog scale } & Before nebulization & 14 & 9.0 & $(8-10)$ & 12 & 8.0 & $(7-10)$ & .52 \\
\hline & During nebulization & 14 & 9.0 & $(8-9)$ & 12 & 4.0 & $(3-7)$ & .001 \\
\hline & After nebulization & 12 & 9.0 & $(8-10)$ & 12 & 7.0 & $(5-8)$ & .04 \\
\hline Numerical rating scale & & 11 & 4.0 & $(3-4)$ & 12 & 2.0 & $(1-2)$ & .001 \\
\hline
\end{tabular}

and after the nebulization, so it is during the actual use of the device that the nebulizer with HFNC system is clearly superior to the jet nebulizer system.

The COMFORT-B scale has gained a place in pediatric intensive care settings worldwide, ${ }^{35}$ and it has been used in hospitalized patients $<3$ y old. ${ }^{36}$ With the aim of avoiding possible inter observer variability, the COMFORT-B scale, visual analog scale, and numeric rating scale scores were assessed by 2 nurses, and we found a strong positive correlation between the 2 examiners. It is possible that the previous training of our health personnel may have influenced these positive results, and this finding reinforces the use of these scales as a measurement of comfort if they are used by qualified health personnel. ${ }^{37}$

The visual analog scale has been shown to be valid as a proxy measure recorded by an experienced person, such as a child's caregiver. ${ }^{38,39}$ Importantly, as others have also reported, we found a strong association between the visual analog scale and the COMFORT-B scale rating. ${ }^{36}$ This association is extendable to the numeric satisfaction rating scale. Comfort and satisfaction can be understood as complementary variables that seek to express a similar objective: to evaluate the level of wellbeing of the patient.

One of the strengths of this study was the analysis of other variables that could have an influence on the results of comfort. In ICUs, greater discomfort has been described during the day compared to during the night due to the presence of increased noise, the number of health personnel, and other factors..$^{40}$ In our case, nebulization with each system was alternated, and day/night distribution was similar in both groups. Likewise, time since the last food intake, which also has an effect on comfort, ${ }^{41}$ was comparable in the 2 groups. Additionally, there were no differences in the use of analgesia, which was not needed in any of the groups. ${ }^{42}$ In any case, the advantages of the nebulizer with HFNC system include avoiding discontinuation of respiratory support, promoting sleep, ${ }^{22}$ and liberating the oral route to allow nebulization during feeding (breast feeding or oral eating), which may influence the course of the disease and reduce family stress. ${ }^{17,43}$

Our study has some limitations. First, the small number of subjects included in this study decreases its external validity, and care should be taken when drawing conclusions about the differences between subjects in comfort for these nebulization methods. However, the 113 measurements we obtained from those 6 subjects, increase the power and precision of the estimations by decreasing intermeasurement variability. Second, we did not take into account other variables that could influence comfort and satisfaction, such as the use of pacifiers or the administration of nebulizations in the parents' arms. On the other hand, although it was not the objective of this work, the study design could not research if delivering an aerosolized bronchodilator through HFNC may induce a significant clinical effect. ${ }^{19}$ Our results showed comparable $\mathrm{O}_{2}$ 
Table 2. Characteristics of Each Nebulization According to Nebulizer System

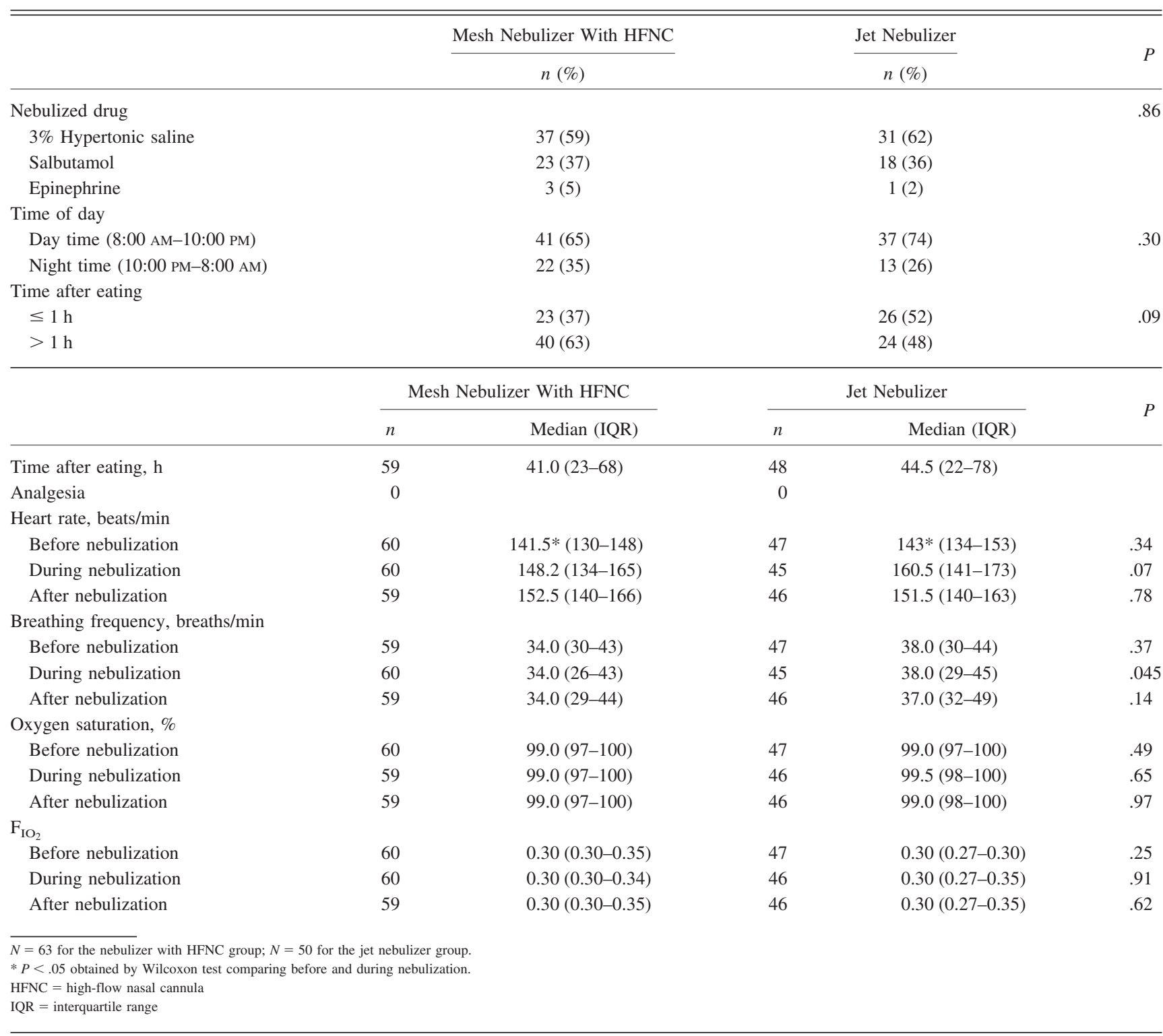

need and $\mathrm{O}_{2}$ saturation before and after the nebulization between both systems. We did find increased heart rate during nebulization compared to previous baseline levels in the conventional jet nebulizer group and nebulizer with HFNC group. The clinical perception and the adequate comfort results obtained during use of the nebulizer with HFNC suggest that the increase in heart rate may be mostly due to the chronotropic effect of the drugs, although in the case of the jet nebulizer system the discomfort of the patient may also play a role. Morgan et $\mathrm{al}^{22}$ described in a case series that heart rate increased to a greater degree with HFNC and the Aerogen Solo than with the jet nebulizer and face mask. However, the aim of this study was not to recommend the use of nebulizations in this disease, but to encourage health professional to bear the patient's comfort in mind, and we insist that further studies are needed to consolidate such therapeutic efficacy.

\section{Conclusions}

Currently, bronchiolitis is a medical frustration, often with slow recovery and with a limited choice of therapeutic options. Ensuring comfort should be an intrinsic prerequisite to any treatment, especially if it has not demonstrated consistent efficacy. HFNC is a frequently used respiratory support in this pathology, and aerosol therapy with a vibrating mesh nebulizer integrated into HFNC generated more comfort and satisfaction than the standard 


\section{Nebulizer With HFNC in Bronchiolitis}

nebulization with a jet nebulizer connected to a face mask. Studies are necessary to demonstrate whether this therapy improves the clinical course of this pathology.

\section{REFERENCES}

1. Viswanathan M, King VJ, Bordley C, Honeycutt AA, Wittenborn J, Jackman AM, et al. Management of bronchiolitis in infants and children. Evid Rep Technol Assess (Summ) 2003(69):1-5.

2. Shay DK, Holman RC, Newman RD, Liu LL, Stout JW, Anderson LJ. Bronchiolitis-associated hospitalizations among US children, 1980-1996. JAMA 1999;282(15):1440-1446.

3. Hall CB, Weinberg GA, Blumkin AK, Edwards KM, Staat MA, Schultz AF, et al. Respiratory syncytial virus-associated hospitalizations among children less than 24 months of age. Pediatrics 2013; 132(2):341-348

4. Diez-Domingo J, Perez-Yarza EG, Melero JA, Sanchez-Luna M, Aguilar MD, Blasco AJ, et al. Social, economic, and health impact of the respiratory syncytial virus: a systematic search. BMC Infect Dis 2014;14:544.

5. Gil-Prieto R, Gonzalez-Escalada A, Marin-Garcia P, Gallardo-Pino C, Gil-de-Miguel A. Respiratory syncytial virus bronchiolitis in children up to 5 years of age in spain: epidemiology and comorbidities: an observational study. Medicine (Baltimore) 2015;94(21):831.

6. Lapillonne A, Regnault A, Gournay V, Gouyon JB, Gilet H, Anghelescu D, et al. Impact on parents of bronchiolitis hospitalization of full-term, preterm and congenital heart disease infants. BMC Pediatr 2012;12:171.

7. Walsh P, Rothenberg SJ. American Academy of Pediatrics 2014 bronchiolitis guidelines: bonfire of the evidence. West J Emerg Med 2015;16(1):85-88

8. Zhang L, Mendoza-Sassi RA, Wainwright C, Klassen TP. Nebulised hypertonic saline solution for acute bronchiolitis in infants. Cochrane Database Syst Rev 2013(7):CD006458.

9. Chen YJ, Lee WL, Wang CM, Chou HH. Nebulized hypertonic saline treatment reduces both rate and duration of hospitalization for acute bronchiolitis in infants: an updated meta-analysis. Pediatr Neonatol 2014;55(6):431-438.

10. Castro-Rodriguez JA, Rodriguez-Martinez CE, Sossa-Briceno MP. Principal findings of systematic reviews for the management of acute bronchiolitis in children. Paediatr Respir Rev 2015;16(4):267-275.

11. Zhang L, Mendoza-Sassi RA, Klassen TP, Wainwright C. Nebulized hypertonic saline for acute bronchiolitis: a systematic review. Pediatrics 2015;136(4):687-701.

12. Coates AL, Ho SL. Drug administration by jet nebulization. Pediatr Pulmonol 1998;26(6):412-423.

13. Amirav I, Balanov I, Gorenberg M, Luder AS, Newhouse MT, Groshar D. Beta-agonist aerosol distribution in respiratory syncytial virus bronchiolitis in infants. J Nucl Med 2002;43(4):487-491.

14. Janssens HM, Tiddens HA. Aerosol therapy: the special needs of young children. Paediatr Respir Rev 2006;7(Suppl):S83-S85.

15. Amirav I, Borojeni AA, Halamish A, Newhouse MT, Golshahi L. Nasal versus oral aerosol delivery to the "lungs" in infants and toddlers. Pediatr Pulmonol 2014;50(3):276-283.

16. Ashok P S, Sabrina M. Respiratory pathophysiology and regulation. Saunders;2014;1-53.

17. Da Dalt L, Bressan S, Martinolli F, Perilongo G, Baraldi E. Treatment of bronchiolitis: state of the art. Early Hum Dev 2013;89(Suppl): S31-S36.

18. McKiernan C, Chua LC, Visintainer PF, Allen H. High flow nasal cannulae therapy in infants with bronchiolitis. J Pediatr 2010;156(4): 634-638.

19. Reminiac F, Vecellio L, Heuze-Vourc'h N, Petitcollin A, Respaud R, Cabrera M, et al. Aerosol therapy in adults receiving high flow nasal cannula oxygen therapy. J Aerosol Med Pulm Drug Deliv 2016; 29(2):134-141

20. Ari A, Atalay OT, Harwood R, Sheard MM, Aljamhan EA, Fink JB. Influence of nebulizer type, position, and bias flow on aerosol drug delivery in simulated pediatric and adult lung models during mechanical ventilation. Respir Care 2010;55(7):845-851.

21. Ari A, Harwood R, Sheard M, Dailey P, Fink JB. In vitro comparison of heliox and oxygen in aerosol delivery using pediatric high flow nasal cannula. Pediatr Pulmonol 2011;46(8):795-801.

22. Morgan SE, Mosakowski S, Solano P, Hall JB, Tung A. High-flow nasal cannula and aerosolized beta agonists for rescue therapy in children with bronchiolitis: a case series. Respir Care 2015;60(9): e161-e165.

23. Pons M, Caritg J, Palomeque A. Bronquiolitis. In: López J, Calvo C, Rey C, Rodriguez A, Baltodano A. Manual de Cuidados Intensivos Pediátricos, 4nd ed. Spain: Publimed Publicación Libros Médicos; 2013: 114-120.

24. Carnevale FA, Razack S. An item analysis of the COMFORT scale in a pediatric intensive care unit. Pediatr Crit Care Med 2002;3(2): 177-180.

25. van Dijk M, Koot HM, Saad HH, Tibboel D, Passchier J. Observational visual analog scale in pediatric pain assessment: useful tool or good riddance? Clin J Pain 2002;18(5):310-316.

26. Faul F, Erdfelder E, Buchner A, Lang AG. Statistical power analyses using $\mathrm{G}^{*}$ Power 3.1: tests for correlation and regression analyses. Behavior Research Methods 2009;41:1149-1160.

27. Bressan S, Balzani M, Krauss B, Pettenazzo A, Zanconato S, Baraldi E. High-flow nasal cannula oxygen for bronchiolitis in a pediatric ward: a pilot study. Eur J Pediatr 2013;172(12):1649-1656.

28. Kelly GS, Simon HK, Sturm JJ. High-flow nasal cannula use in children with respiratory distress in the emergency department: predicting the need for subsequent intubation. Pediatr Emerg Care 2013; 29(8):888-892

29. Reminiac F, Vecellio L, Loughlin RM, Le Pennec D, Cabrera M, Vourc'h NH, et al. Nasal high flow nebulization in infants and toddlers: an in vitro and in vivo scintigraphic study. Pediatr Pulmonol 2017;52(3):337-344

30. Nelson JE, Puntillo KA, Pronovost PJ, Walker AS, McAdam JL, Ilaoa $\mathrm{D}$, et al. In their own words: patients and families define high-quality palliative care in the intensive care unit. Crit Care Med 2010;38(3):808-818.

31. Sahin B, Yilmaz F, Lee KH. Factors affecting inpatient satisfaction: structural equation modeling. J Med Syst 2007;31(1):9-16.

32. Wood DL, McCaskill QE, Winterbauer N, Jobli E, Hou T, Wludyka PS, et al. A multi-method assessment of satisfaction with services in the medical home by parents of children and youth with special health care needs (CYSHCN). Matern Child Health J 2009;13(1):5-17.

33. Wall RJ, Engelberg RA, Downey L, Heyland DK, Curtis JR. Refinement, scoring, and validation of the Family Satisfaction in the Intensive Care Unit (FS-ICU) survey. Crit Care Med 2007;35(1):271-279.

34. Cole CH. Special problems in aerosol delivery: neonatal and pediatric considerations. Respir Care 2000;45(6):646-651.

35. Bai J, Hsu L, Tang Y, van Dijk M. Validation of the COMFORT Behavior scale and the FLACC scale for pain assessment in Chinese children after cardiac surgery. Pain Manag Nurs 2012;13(1):18-26.

36. van Dijk M, de Boer JB, Koot HM, Tibboel D, Passchier J, Duivenvoorden HJ. The reliability and validity of the COMFORT scale as a postoperative pain instrument in 0 to 3 -year-old infants. Pain 2000; 84(2-3):367-377.

37. Beytut D, Basbakkal Z, Karapinar B. Validity and reliability study of sedation diagnosis method comfort scale. Agri 2016;28(2):89-97.

38. Agence Nationale d'Accreditation et d'evaluation en S. Evaluation and management strategies for acute pain in ambulatory care of children aged 1 month to 15 years. Text of the recommendations of 


\section{Nebulizer With HFNC IN BRONChiolitis}

the National Agency for Health Accreditation and Evaluation. Arch Pediatr 2001;8(4):420-432.

39. Traivaree C, Jindakam W, Monsereenusorn C, Rujkijyanont $\mathrm{P}$, Lum$\mathrm{kul} \mathrm{R}$. The factors of ketamine that affect sedation in children with oncology procedures: parent satisfaction perspective. J Med Assoc Thai 2014;97(Suppl):S19-S24.

40. Ista E, van Dijk M, Tibboel D, de Hoog M. Assessment of sedation levels in pediatric intensive care patients can be improved by using the COMFORT "behavior" scale. Pediatr Crit Care Med 2005;6(1): 58-63.
41. Ward JJ. High-flow oxygen administration by nasal cannula for adult and perinatal patients. Respir Care 2013;58(1):98-122.

42. Boerlage AA, Ista E, Duivenvoorden HJ, de Wildt SN, Tibboel D, van Dijk M. The COMFORT behaviour scale detects clinically meaningful effects of analgesic and sedative treatment. Eur J Pain 2015; 19(4):473-479.

43. Janssens HM, van der Wiel EC, Verbraak AF, de Jongste JC, Merkus PJ, Tiddens HA. Aerosol therapy and the fighting toddler: is administration during sleep an alternative? J Aerosol Med 2003;16(4):395400 . 